\title{
A GENERAL FOURTH-ORDER PARABOLIC EQUATION
}

\author{
CHAO ZHANG AND SHULIN ZHOU
}

Abstract. In this paper we establish the existence and uniqueness of weak solutions for the initial-boundary value problem of a general fourth-order parabolic equation. Our assumptions are much weaker than those in the literature.

Mathematics subject classification (2010): 35D05, 35G20.

Keywords and phrases: existence, uniqueness, fourth-order parabolic equations.

\section{REFERENCES}

[1] Y. CAI, S. ZHOU, Existence and uniqueness of weak solutions for a non-uniformly parabolic equation, J. Funct. Anal., (2009), doi:10.1016/j.jfa.2009.08.007.

[2] S. Chapman, T. G. Cowling, Mathematical theory of nonuniform gases, 3rd edition, Cambridge University Press, 1990.

[3] Y. Chen, Parabolic partial differential equations of second order, Peking University Press, Beijing, 2003 (in Chinese).

[4] B. Dacorogna, Direct methods in the caculus of variations, Springer-Verlg, Berlin-Heidelberg, 1989.

[5] E. DiBenedetto, Degenerate parabolic equations, Springer, Berlin, 1993.

[6] R. J. Diperna, P.-L. Lions, On the Cauchy problem for Bolzmann equations: global existence and weak stability, Ann. of Math., 130, 2 (1989), 321-336.

[7] D. M. Duc, J. Eells, Regularity of exponetional harmonic functions, Intern. J. Math., 2 (1991), 395-408.

[8] L. C. Evans, Partial differential equations, Amer. Math. Soc., Providence, Rhode Island, 1998.

[9] M. Fuchs, G. Mingione, Full $C^{1, \alpha}$-regularity for free and contrained local minimizers of elliptic variational integrals with nearly linear growth, Manuscripta Math., 102, 2 (2000), 227-250.

[10] D. Gilbarg, N. Trudinger, Elliptic partial differential equations of second order, second ed., Springer, Berlin, 1983.

[11] J.-B. HiRiart-Urruty, C. Lemaréchal, Fundamentals of convex analysis, Springer-Verlag, Berlin-Heidelberg, 2001.

[12] G. M. Liebberman, On the regularity of the minimizer of a functional with exponetial growth, Comment. Math. Univ. Carolinae., 33, 1 (1992), 45-49.

[13] J.-L. Lions, Quelques méthodes de résolution des problèmes aux limites non linéaire, Dunod et Gauthier-Villars, Paris, 1969.

[14] H. L. Royden, Real analysis, 2nd edition, Macmillan Company, New York, 1968.

[15] M. SAAdoune, M. VAladier, Extraction of a "good" subsequence from a bounded sequence of integrable functions, Journal of Convex Analysis, 2 (1995), 345-357.

[16] L. WANG, S. ZHOU, Existence and uniqueness of weak solutions for a nonlinear parabolic equation related to image analysis, J. Partial Differential Equations, 19, 2 (2006), 97-112.

[17] M. XU, S. ZHOU, Existence and uniqueness of weak solutions for a fourth-order nonlinear parabolic equation, J. Math. Anal. Appl., 325 (2007), 636-654.

[18] S. ZHOU, A priori $L^{\infty}$-estimate and existence of weak solutions for some nonlinear parabolic equations, Nonlinear Anal., 42 (2000), 887-904. 